\title{
Formação de Atitudes em Relação à Matemática na Licenciatura em Pedagogia no Contexto de um Projeto de Investigação
}

\author{
Formation of Attitudes towards Mathematics in the Degree in Pedagogy \\ in the Context of a Research Project
}

\author{
Cíntia Raquel Ferreira Mercado de Almeida (cintiarfm@gmail.com) \\ Instituto de Matemática (INMA) - Universidade Federal de Mato Grosso do Sul (UFMS)
}

Klinger Teodoro Ciríaco (klinger.ciriaco@ufscar.br)

Departamento de Teorias e Práticas Pedagógicas (DTPP) - Universidade Federal de São Carlos (UFSCar)

Resumo: Descrevemos resultados de uma dissertação de mestrado, do Programa de Pós-Graduação em Educação Matemática da Universidade Federal de Mato Grosso do Sul - UFMS, que tem como objetivo compreender em que medida práticas desenvolvidas no curso de Pedagogia aproximam e/ou distanciam os futuros pedagogos da Matemática, bem como quais atitudes estes acadêmicos estruturam durante a disciplina responsável pela abordagem de conteúdos e metodologias ligados ao conhecimento matemático. O referencial teórico abarca questões da Psicologia da Educação Matemática relacionadas à atitudes. Os dados foram produzidos na realização do estágio docência na disciplina "Fundamentos e Metodologias do Ensino de Matemática" a partir de uma pesquisa qualitativa com observação participante. Os resultados apontam que embora a carga horária seja considerada insuficiente, contribuiu para superação de alguns dos medos, os futuros professores parecem ter desenvolvido confiança para romper com o elo de não reproduzir em sua prática pontos negativos que vivenciaram durante sua Educação Básica.

Palavras-chave: Psicologia da Educação Matemática; Formação Inicial; Pedagogia; Atitudes.

\begin{abstract}
We describe the results of a master's thesis, from the Postgraduate Program in Mathematical Education at the Federal University of Mato Grosso do Sul - UFMS, which aims to understand the extent to which practices developed in the Pedagogy course bring and / or distance future educators Mathematics, as well as what attitudes these academics structure during the discipline responsible for approaching content and methodologies related to mathematical knowledge. The theoretical framework encompasses issues of the Psychology of Mathematics Education related to attitudes. The data were produced during the teaching internship in the discipline "Fundamentals and Methodologies of Teaching Mathematics" from a qualitative research with participant observation. The results show that although the workload is considered insufficient, it contributed to overcome some of the fears, future teachers seem to have developed confidence to break the link of not reproducing negative points in their practice that they experienced during their Basic Education.
\end{abstract}

Keywords: Psychology of Mathematics Education; Initial formation; Pedagogy; Attitudes.

Recebido em: $30 / 03 / 2020$

Aceito em: 18/09/2020 


\section{INTRODUÇÃO}

Relatamos, neste artigo, encaminhamentos e resultados parciais de um projeto de investigação vinculado ao Programa de Pós-Graduação em Educação Matemática vinculada (curso de mestrado) do Instituto de Matemática (INMA) da Universidade Federal de Mato Grosso do Sul (UFMS), Campo Grande. Temos como objetivo compreender as atitudes que estudantes de um curso de Pedagogia têm frente as práticas formativas durante a disciplina responsável pela abordagem dos conteúdos e metodologias ligados ao conhecimento matemático.

Para este fim, recorremos ao trabalho no campo da Psicologia da Educação Matemática, especificamente ao conceituarmos e estudarmos a formação de atitudes das estudantes de um curso de Pedagogia em relação à Matemática. Em termos metodológicos, os dados foram produzidos no contexto da realização do estágio docência da pós-graduação da primeira autora na disciplina "Fundamentos e Metodologias do Ensino de Matemática", na Faculdade de Educação da UFMS, com carga horária de 68 horas, a partir de uma pesquisa qualitativa em que a observação participante fora o elemento central do processo de caracterização da realidade vivenciada pela pesquisadora.

Estruturamos o artigo em 4 seções, além da introdução, as quais terão o objetivo de discutir a presença da Matemática em cursos de Pedagogia e a formação de atitudes dos professores; procedimentos metodológicos; descrição e análise de dados em que nos propusemos a analisar uma escala de atitudes e correlacioná-la com as primeiras impressões do movimento de aproximação com a realidade investigada e que compõe o cenário da elaboração da dissertação de mestrado que estamos a desenvolver desde março de 2019; e, por fim, são apresentadas as considerações finais que demarcam os próximos passos do projeto.

\section{REFERENCIAL TEÓRICO}

No campo da Psicologia da Educação Matemática (PEM), a concepção do conhecimento matemático é o resultado de construções que os indivíduos realizam em contextos específicos como, por exemplo, na relação que se estabelece com um 
determinado conceito ao longo da vida em decorrência de experiências práticas e/ou teóricas com ele.

Para Ponte (1995), a ação dos professores e o seu modo de estar são determinantes e criam marcas nas aprendizagens dos alunos com quem vivencia diariamente. Neste contexto, observamos que é fundamental a contribuição dos professores quando se pretende realizar mudanças significativas na área da educação, razão pela qual o desenvolvimento de um conhecimento especializado para si pode contribuir para o processo de aprendizagem para o outro (aluno).

Sobre essa questão, Gonçalez (1995) afirma que embora seja atribuída a escola a função de transmissão ${ }^{1}$ de conhecimento, as atitudes e, consequentemente, seu desenvolvimento são reconhecidos como essenciais no processo de ensino e da aprendizagem. Logo, a compreensão das atitudes torna-se elemento/pressuposto inicial para o planejamento, a avaliação e o entendimento do aprender Matemática.

Brito (1996, p. 26) conceitua o termo atitude como:

[...] uma disposição pessoal, idiossincrática, presente em todos os indivíduos, dirigida a objetos, eventos ou pessoas, que assume diferente direção e intensidade de acordo com as experiências do indivíduo. Além disso, apresenta componentes do domínio afetivo, cognitivo e motor.

É importante ressaltar que este termo possui um referente, concerne à "atitude com relação a". As atitudes são adquiridas e variam ao longo da vida, a autora afirma que elas são altamente suscetíveis às influências da cultura na qual o indivíduo se encontra, está inserido e como as atitudes são apreendidas, a escola pode e deve ensinálas. Assim, compreender as atitudes em relação à Matemática, significa buscar as experiências que o indivíduo teve com a disciplina e compreendê-las dentro do contexto em que elas se desenvolveram (BRITO, 1996).

Brito (1996), ao adaptar a definição de Stanger (1937), conceitua que a atitude em relação à Matemática se caracteriza por um objeto (conteúdo matemático), uma direção (positiva ou negativa) e uma intensidade (gostar da ou ter aversão à Matemática). Isso exige dos professores atitudes que, muitas vezes, eles também não têm. A autora ressalta ainda a importância de mudança de atitudes na formação inicial de professores, o que envolve uma mudança de atitudes dos indivíduos acerca do ensino e a formação

\footnotetext{
${ }^{1}$ Termo presente no trabalho de Gonçalez (1995).
} 
profissional nas Universidades no sentido de favorecer momentos para que os futuros professores possam se libertar dos traumas, medos e dissabores com o conhecimento matemático.

Não obstante, Faria (1996) ao desenvolver sua dissertação de mestrado em educação constatou que a atitude em relação à Matemática não é uma dimensão trabalhada nos cursos de licenciatura, a própria disciplina referente aos saberes/conhecimentos matemáticos aparece de forma fragmentada, razão pela qual a formação centra-se em metodologias de ensino, visando no "como ensinar" e não "no que se ensinar" (em termos de conteúdos), o que acaba não contribuindo para a formação específica dos futuros professores (CURI, 2004).

Em sua tese de doutorado, há mais de uma década, Curi (2004 p. 8) afirmou que "[...] as disciplinas relativas à matemática e seu ensino que constam das grades curriculares dos cursos de pedagogia têm uma carga horária bastante reduzida [...]", entre 60 e 78 horas com apenas uma disciplina para tratar dos conteúdos e seu ensino "[...] uma concepção dominante de que o professor polivalente não precisa 'saber Matemática' e que basta saber como ensiná-la" (CURI, 2004, p. 77). Tal estudo revelou que a maioria das grades curriculares, dos cursos de Pedagogia analisados na época pela autora, priorizavam a disciplina de "Metodologia do Ensino de Matemática", sendo estas voltadas para os aspectos metodológicos, "[...] o conhecimento "de e sobre" matemática é muito pouco enfatizado" (IDEM, p. 69).

A título de contextualização, ainda estamos a vivenciar a mesma realidade apontada por Curi (2004), mesmo tendo, em 2020, alguns pareceres e diretrizes de formação de professores que não estavam vigentes quando do momento da realização do estudo da pesquisadora. Ilustramos este fato porque, no caso de nossa investigação, na UFMS, onde a produção de dados foi realizada, a disciplina conta com uma carga horária de 68 horas e é ministrada no $4^{\circ}$ (quarto) semestre, ou seja, no final do $2^{\circ}$ (segundo) ano da licenciatura, ou seja, poucas mudanças foram realizadas no contexto formativo no que respeita a abordagem/presença da Matemática em cursos de Pedagogia. Dadas tais características, é possível concordar com a autora que demonstrou que o modo como o conhecimento matemático é abordado na formação inicial, pouco contribui para que os futuros pedagogos aprendam a conhecer a Matemática, como ensiná-la e o modo como o aluno aprende. Portanto: 


\begin{abstract}
É possível considerar que os futuros professores concluem cursos de formação sem conhecimentos de conteúdos matemáticos com os quais irão trabalhar, tanto no que concerne a conceitos quanto a procedimentos, como também da própria linguagem matemática que utilizarão em sua prática docente. Em outras palavras, parece haver uma concepção de que o professor polivalente não precisa "saber Matemática" e que basta saber como ensiná-la (CURI, p. 76-77).
\end{abstract}

Seguindo o mesmo pensamento, Fiorentini (2008, p. 57), apoia que a carga horária dedicada à Matemática no curso de Pedagogia é insuficiente. Para ele:

\begin{abstract}
A reduzida carga didática que os cursos de Pedagogia e Licenciatura para as séries iniciais do Ensino Fundamental têm destinado à formação conceitual e didático-pedagógica da matemática tem sido um problema crônico e que não foi contemplado pelas atuais Diretrizes Curriculares. Além da falta de um domínio conceitual da matéria, os alunos-docentes que ingressam nesses cursos de formação docente trazem crenças e atitudes geralmente negativas e pré-conceituosas em relação à matemática e seu ensino. Relação essa decorrente de uma historia de fracasso escolar e da construção de uma imagem de que matemática é difícil e que nem todos são capazes de aprendê-
\end{abstract} la.

Nacarato, Mengali e Passos (2009, p. 22) ressaltam que "[...] as futuras professoras polivalentes têm tido poucas oportunidades para uma formação matemática que possa fazer frente às atuais exigências da sociedade e, quando ela ocorre na formação inicial, vem sendo pautada nos aspectos metodológicos [...]". Com isso, por muitas vezes, torna esse profissional "reprodutor" de suas experiências adquiridas como aluno, ensinando seus futuros alunos da mesma forma com que aprendeu (CIRÍACO; TEIXEIRA, 2014).

Gomes (2006, p. 53), ao estudar os obstáculos epistemológicos na aprendizagem matemática de futuros professores, reforça "[...] se aprenderam a detestar a matemática, farão uma nova geração detestá-la; se aprenderam a aplicar fórmulas e técnicas, é assim que seus alunos também aprenderão [...]", tal assertiva corrobora com dados de outras investigações, aqui nos referimos as do campo da Psicologia da Educação Matemática, as quais denunciam que, de acordo com Moraes e Pirola (2015), atitudes negativas frente à Matemática podem acarretar inúmeros equívocos de natureza didática e conceituais, como também contribuir, de forma significativa, para que as crianças não tenham experiências significativas nas tarefas matemáticas propostas em sala de aula.

Frente ao referencial teórico adotado por nós, acreditamos ser necessário olhar de modo cuidadoso para a forma como está se propondo a formação inicial de professores, especificamente em como a Educação Matemática no início da escolarização é 
abordada, os conhecimentos, saberes e metodologias de ensino apresentadas aos estudantes do Ensino Superior. É compreendendo o papel que o professor formador pode desempenhar neste momento que defendemos o posicionamento teórico $\mathrm{e}$ metodológico de que é na formação inicial que grande parte das atitudes poderiam ser ressignificadas.

\section{DELINEAMENTO METODOLÓGICO}

A pesquisa se inscreve no campo dos estudos qualitativos, de caráter descritivoanalítico, buscando verificar como são as práticas e metodologia que o professor formador adota na disciplina relacionada à Matemática em um curso de licenciatura em Pedagogia. Para este fim, delineamos um trabalho de campo focando em identificar como a disciplina oportuniza, para os estudantes, a formação de "atitudes" (tanto positivas quanto negativas). Ou seja, quais fatores evidenciam o fortalecimento de experiências que geram processos de aprendizagem no adulto-futuro-professor.

A abordagem qualitativa na pesquisa em educação permite ao pesquisador estar em contato direto com o contexto e situação investigada, bem como discutir os resultados a partir de inferências com base em um referencial teórico. Neste sentido, "[...] um fenômeno pode ser melhor compreendido no contexto em que ocorre e do qual é parte, devendo ser analisado numa perspectiva integrada" (GODOY, 1995, p. 21). Conforme Minayo (2013), a observação participante se faz necessária por ser considerada como parte essencial do trabalho de campo na pesquisa qualitativa. A autora define observação participante como:

\footnotetext{
Um processo pelo qual um pesquisador se coloca como observador de uma situação social com a finalidade de realizar uma investigação científica. $\mathrm{O}$ observador, no caso, fica em relação direta com seus interlocutores no espaço social da pesquisa, na medida do possível, participando da vida social deles, no seu cenário cultural, mas com a finalidade de compreender o contexto da pesquisa. Por isso, o observador faz parte do contexto sob sua observação e, sem dúvida, modifica esse contexto, pois interfere nele, assim como é modificado pessoalmente (MINAYO, 2013, p. 70).
}

A observação tem um sentido prático e permite ao pesquisador desprender-se de prejulgamentos e de interpretações prontas, uma vez que é no convívio com o grupo estudado que o observador percebe as questões realmente relevantes e que compreende aspectos que, aos poucos, vão aflorando. 
Dito isso, a produção de dados ocorreu concomitante com atividades do "Estágio Docência no Ensino Superior ${ }^{2 "}$. A primeira autora participou de todas as aulas juntamente com os alunos do curso de Pedagogia, realizou a observação das interações ocorridas entre professora formadora e futuros professores, captou os processos de ensino adotados durante o segundo semestre letivo de 2019. A disciplina acompanhada foi ofertada em um dia da semana no período matutino, das 7 h30min às $11 \mathrm{~h} 30 \mathrm{~min}$, iniciou com 49 (quarenta e nove) estudantes. Dentre o número de alunos regularmente matriculados, 23 (vinte e três) se dispuseram a contribuir com todas as etapas da produção de dados para sequência desta pesquisa. A faixa etária dos colaboradores compreende de 18 (dezoito) a 46 (quarenta e seis) anos, a maioria mulheres, egressas de escolas públicas que terminaram o Ensino Médio entre os anos de 1994 até 2017. De acordo com os dados coligidos, via questionário inicial de caracterização os sujeitos, embora alguns tenham optado por Pedagogia por não terem conseguido a pontuação para fazer o "curso dos seus sonhos", grande parte optou pela licenciatura por se identificar com a área e acreditar ter um mercado de trabalho promissor e com a inserção mais rápida na carreira.

A dinâmica de produção de dados, na disciplina acompanhada, valeu-se de atividades práticas realizadas pelos estudantes como, por exemplo, a escrita de um texto narrativo intitulado "A Matemática e Eu", cujo objetivo era que descrevessem as experiências com a Matemática ao longo da Educação Básica. Como entendemos que tal atividade possibilita compreendermos alguns medos, anseios, expectativas de se ver como futuro professor e o que esperavam da disciplina, julgamos pertinente adotar a inclusão desta no trabalho de pesquisa, haja vista que tal proposta fora desencadeada pela pesquisadora (mestranda em Educação Matemática) que realizou o estágio na turma de Pedagogia.

Logo, após essa produção, como forma de complementação e cumprindo um item importante da investigação que estamos a desenvolver, convidamos o grupo de estudantes a responderem uma "Escala de Atitudes" em relação à Matemática, desenvolvida por Aiken e Dreger (1961) que foi traduzida, testada, adaptada e validada por Brito (1996). A finalidade é ter acesso sobre as atitudes, neste caso dos acadêmicos

\footnotetext{
${ }^{2}$ Atividade Curricular obrigatória do Bolsista CAPES relacionadas a prática docente visando contribuir para formação profissional como um todo.
} 
em Pedagogia, esta trata-se de "[...] um conjunto de itens que mede uma entidade comum composta de 20 afirmações (10 negativos e 10 positivos)" (BRITO, 1998, p. 126). Além dessas vinte, na validação da escala, foi incluída mais uma afirmação cujo objetivo era avaliar a autopercepção do desempenho em Matemática, pressupostos estes implementados por Britto (1998) e adotado por várias pesquisas em Psicologia da Educação Matemática realizadas pós-validação da autora, a quem devemos os méritos do pioneirismo no contexto brasileiro de estudos deste tipo, como é o caso do nosso.

Faria, Camargo e Moro (2009, p. 32) afirmam que:

\begin{abstract}
A possibilidade de mensuração oferecida pelas escalas de atitudes traz maior precisão e validade aos resultados obtidos. A escolha deste instrumento é importante para a realização da pesquisa ao permitir identificar os graus de aceitação ou rejeição dos participantes em relação à matemática, logo, o tipo de atitude que eles apresentavam em relação à matemática.
\end{abstract}

Como dito, a "Escala de Atitudes" é composta por 21 afirmações que exprimem sentimentos. A análise desta, normalmente, é feita por meio de um critério de divisão e pontuação das respostas da seguinte forma: - sentimentos positivos são as afirmações 3 , $4,5,9,11,14,15,18,19$ e 20) cuja pontuação dessas questões seguem a seguinte lógica: 1 "discordo totalmente"; 2 "discordo"; 3 "concordo"; 4 "concordo totalmente". Já os sentimentos negativos são as afirmações $1,2,6,7,8,10,12,13,16$ e 17, a estas foram atribuídos pontos da mesma forma, porém, de maneira invertida partindo de 1 para "concordo totalmente" e 4 para "discordo totalmente". A escala ainda apresenta uma última afirmação "Não tenho um bom desempenho em Matemática" que verifica a autopercepção do participante.

A pontuação em cada questão pode variar entre 1 a 4 pontos. A exemplo disso, destacamos as imagens abaixo (itens da escala) para compreender melhor como é feita a somatória dos pontos de cada participante:

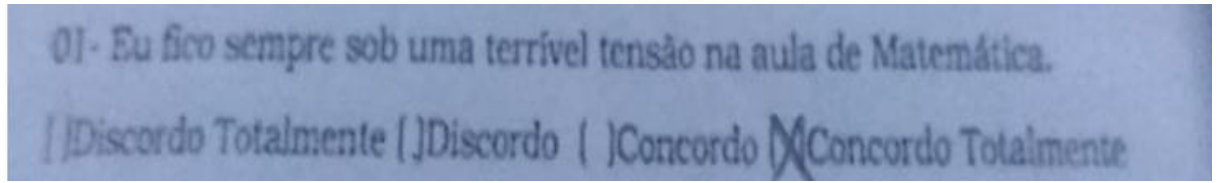

Figura 1 - Afirmação negativa

Fonte: Retirada da resposta questão 1 da Escala de Atitudes Aiken (1961) aplicada, 2019

A figura 1 representa um exemplo de resposta para que possamos esclarecer, de modo mais preciso, como a pontuação da escala é feita (contabilizado). Temos aqui uma 
afirmação negativa em que a pontuação para cada resposta é: 4 para "discordo totalmente" / 3 para "discordo" / 2 para "concordo" e 1 para "concordo totalmente". Neste caso, para a resposta do sujeito, como vimos, o ponto a ser marcado é 1.

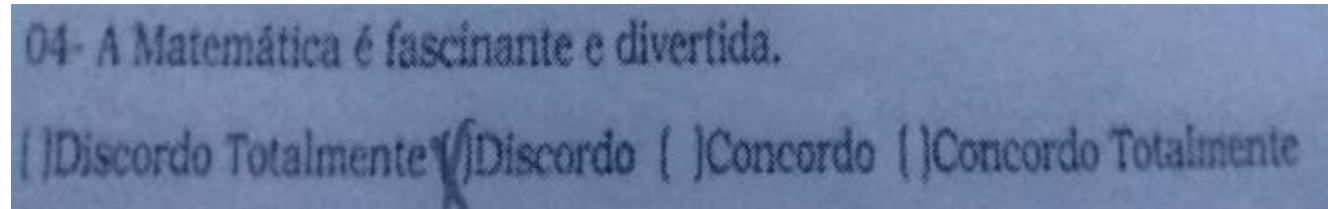

Figura 2 - Afirmação positiva

Fonte: Retirada da resposta questão 4 da Escala de Atitudes Aiken (1961) aplicada, 2019

Já a figura 2 representa uma afirmação positiva na qual a pontuação para cada resposta é: 1 para "discordo totalmente" / 2 para "discordo" / 3 para "concordo" e 4 para "concordo totalmente". Logo, para esta questão, o participante fez 2 pontos, o que já dá para perceber os indícios do seu sentimento ser negativo em relação à Matemática.

Como demonstrado nas figuras 1 e 2, para cada questão respondida, os participantes do estudo podem fazer entre 1 e 4 pontos por meio da somatória dos pontos obtidos em cada afirmação que poderão ser computados no score ao final da análise das respostas, sendo que estas chegam a variar entre 20 e 80 pontos. Contudo, esta é uma escala adaptada de um modelo em que, originalmente havia 20 questões e a $21^{a}$ questão foi acrescentada por Brito (1996), sendo assim esta última questão terá uma análise a parte.

A partir dessa pontuação, é possível calcular a média, o que nos dá parâmetros para afirmar se o grupo apresenta mais tendências para atitudes positivas ou para negativas. Aqueles alunos que tiveram uma pontuação acima da média são considerados participantes que tendem a ter atitudes positivas e os que tiveram pontuação abaixo da média, tendem a ter atitudes negativas.

A média das pontuações dos futuros professores de nossa pesquisa foi de 49.34 pontos. Nessa lógica, 13 (treze) [56,6\%] apresentaram pontuação abaixo da média e 10 (dez) $[43,4 \%]$ pontuações acima da média. Isto posto, percebemos que a maioria dos participantes apresentam atitudes negativas em relação à Matemática. A figura 3 ilustra como foi a distribuição da pontuação: 


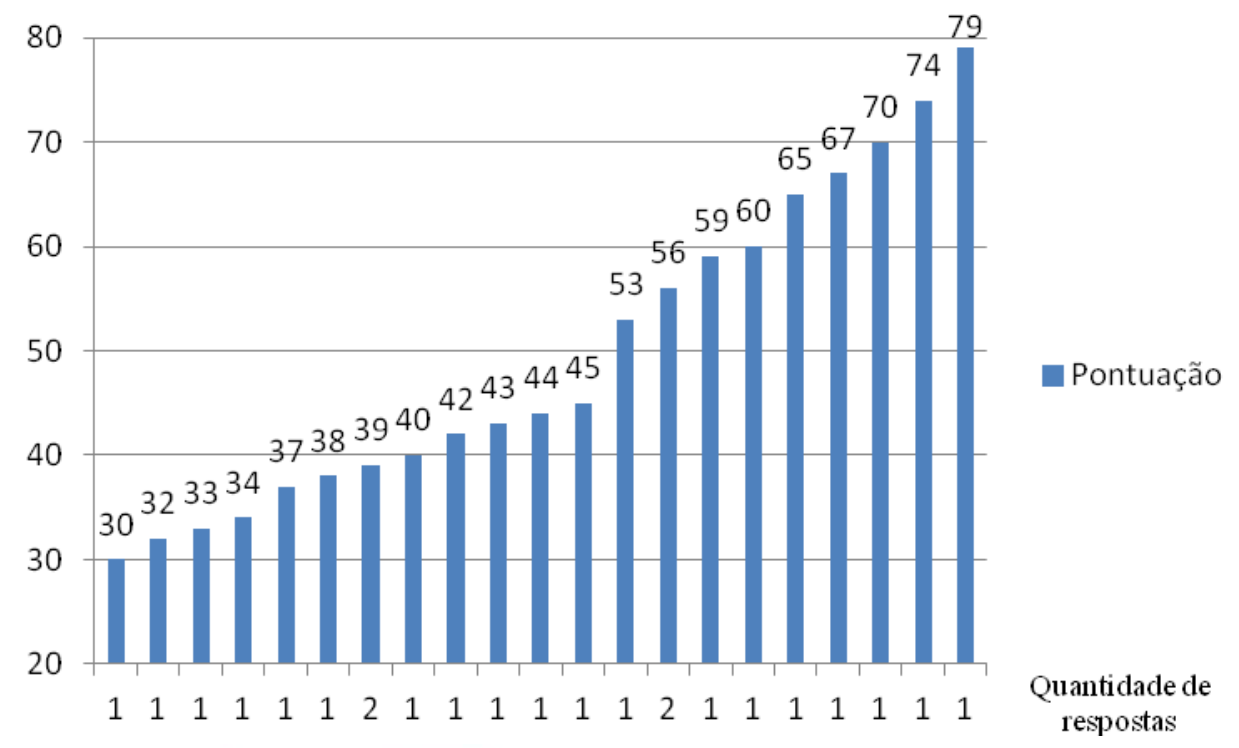

Figura 3 - Pontuação dos futuros professores.

Fonte: Respostas da "Escala de Atitudes" aplicada em 2019 (AIKEN, 1961).

Neste texto, os dados analisados inicialmente caminharam no sentido de articular algumas questões da "Escala de Atitudes" na tentativa de aferir, por meio das respostas, quais são as atitudes de estudantes de Pedagogia frente à Matemática. Dado o fato de que temos 21 questões na escala, selecionamos, nesta etapa da pesquisa, 4 (quatro) questões, as quais os participantes puderam explicitar claramente o que sentem. Destas, 2 (duas) em que é possível perceber atitudes positivas nas respostas para as afirmações:

- N. ${ }^{\circ} 9$ - Os sentimentos que tenho em relação à Matemática é bom e a afirmação;

- N. ${ }^{\circ} 20$ - Eu tenho uma reação definitivamente positiva com relação à Matemática: Eu gosto e aprecio essa matéria;

E 2 (duas) para atitudes negativas:

- N. ${ }^{\circ} 2$ - Eu não gosto de Matemática e me assusta ter que fazer essa matéria;

- N. ${ }^{\circ} 17$ - Eu nunca gostei de Matemática e é a matéria que me dá mais medo.

Outro ponto para obtermos percepções iniciais da relação dos futuros professores com a Matemática foi frente às respostas do questionário composto por 20 (vinte) questões que aplicamos, sendo este desenvolvido logo no começo da disciplina, em meados de agosto de 2019. Em suma, as perguntas que compuseram este instrumentos 
de recolha de informações exploramos aspectos acerca do perfil dos participantes; opção pela Pedagogia como curso superior; experiência com a Matemática ao longo do período de escolarização; características e lembranças das aulas e dos professores que tiveram; expectativas no Ensino Superior a partir das perspectivas com a disciplina de "Fundamentos e Metodologias do Ensino de Matemática", entre outras, as quais serão melhor descritas e analisadas no texto original da dissertação.

Na próxima seção, tentaremos, com base em algumas respostas do questionário e da escala correlacionar os dados para descrever a atitude dos futuros professores em um exercício de esboço inicial de organização da produção do trabalho de mestrado desenvolvido por nós.

\section{DESCRIÇÃO E ANÁLISE DE DADOS}

No que respeita a estrutura da formação matemática e a formação para o ensino de Matemática dos acadêmicos de Pedagogia da Faculdade de Educação na UFMS em 2019.2, a disciplina foi organizada por módulos, tratados da seguinte forma: MI: Conceito de Número/ Adição e Subtração/ Multiplicação e Divisão / Frações / Números Decimais; MII: Álgebra / Pensamento Algébrico; MIII: Geometria / Análise do livro didático; MIV: Grandezas / Medidas e Tratamento da Informação/ Probabilidade e Estatística.

As aulas foram ministradas de forma expositiva pela professora formadora, momentos em que esta iniciava a discussão por meio de slides. Na sequência, exercícios e materiais manipuláveis eram apresentados na perspectiva de exemplificar que poderiam ser utilizados ao explicar um conteúdo matemático, por exemplo material dourado, tangram, sólidos geométricos, ábaco, disco de frações, régua de frações, jogos (bingo, nunca dez, entre outros). Ao final de cada aula, grupos eram organizados para que os alunos pudessem discutir como ensinar o conteúdo abordado de forma lúdica, manuseando os materiais que a professora disponibilizava. Durante as aulas, foi possível perceber que mais do que a dificuldade em "como ensinar" e se tornar um professor que lecionará Matemática, muitos alunos tinham dificuldades relacionadas ao conceito em si, o que os deixavam, por vezes, "perdidos" em pensar como ensinar algo que eles não conhecem. Para nós, do ponto de vista didático-formativo, a pouca carga horária é um fator contributivo para isso, pois como o tempo é relativamente pouco para 
abordagem de todos os campos matemáticos e suas abordagens metodológicas, as discussões acabam centrando-se mais em aspectos de metodologia.

Com base no questionário inicial, solicitamos aos estudantes que descrevessem, com apenas uma palavra, como se sentiam ao pensar que serão futuros professores e que terão de lecionar Matemática nos anos iniciais, particularmente em turmas de $1^{\circ}$ ao $5^{\circ}$ ano. Frente a isso, as respostas demarcam, quanto maior a fonte na nuvem de palavra da figura 4, a frequência com a qual foram escritas:
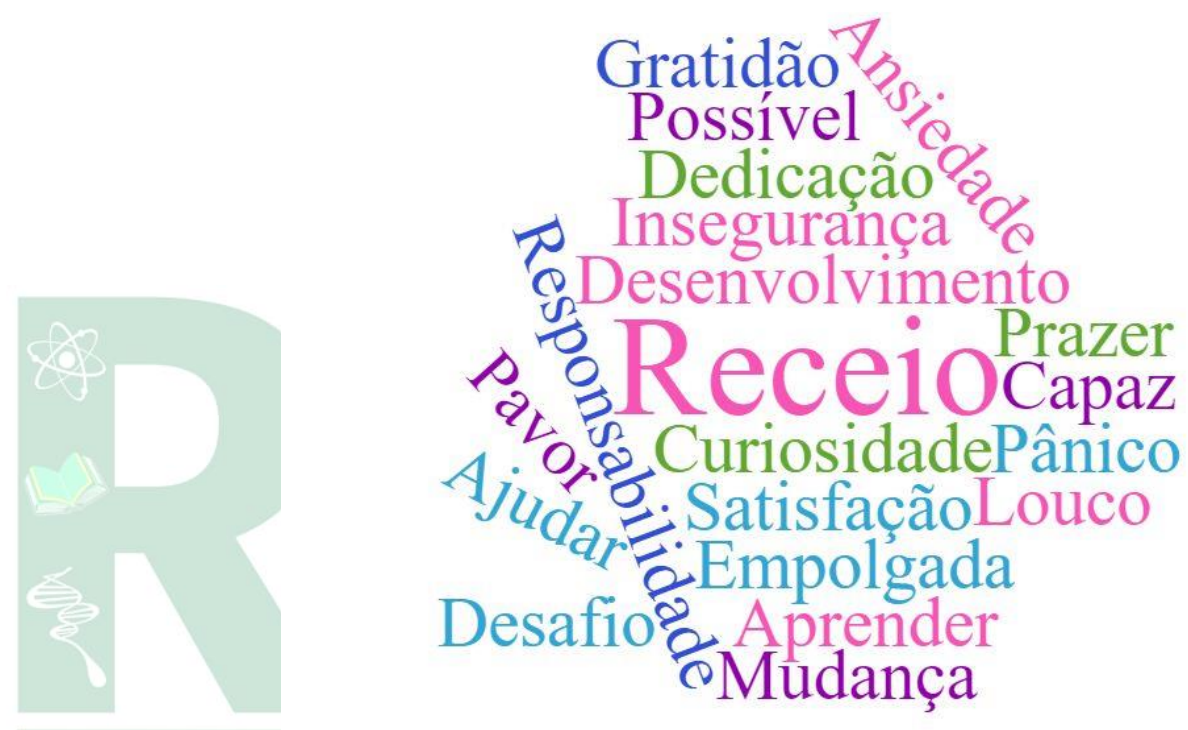

Figura 4 - Sentimentos declarados pelos pedagogos em formação

Fonte: Elaborado com base nas respostas do questionário inicial (questão n. 10), 2019.

Dentre as palavras que agrupam as respostas, podemos dizer que a maior parte são de natureza mais negativas. É possível perceber que a palavra mais citada foi "RECEIO", dado este que corrobora com observações realizadas na sala de aula em que a fala mais comum foi "tenho receio em ensinar o que não domino". Em uma tentativa de evidenciar os sentimentos relacionados à Matemática, apresentaremos parte dos dados, conforme os gráficos gerados a partir das respostas da escala de atitudes. Como dito na seção metodológica, importante ressaltar que 23 [100\%] corresponde ao quantitativo de respostas. 


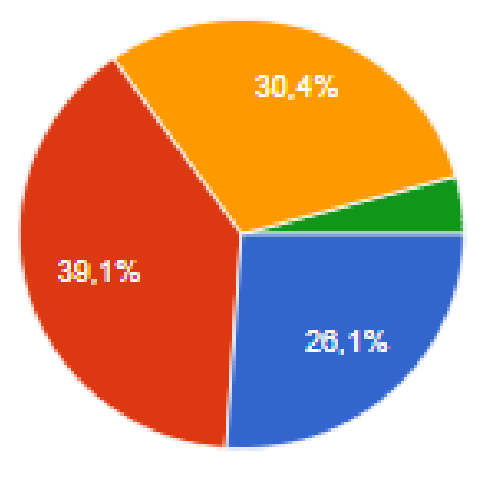

Figura 5 - Gráfico Questão N. ${ }^{\circ}$ 2: "Eu não gosto de Matemática e me assusta ter que fazer essa matéria".

Nesta afirmativa considerada como negativa, observamos que predomina $39.1 \%$ (9) repostas para "discordo"; 30.4\% (7) para "concordam"; 26,1\% (6) "discordo totalmente"; e $4.4 \%$ (1) em "concordo totalmente". É possível perceber que cursar a matéria de Matemática não causa, aparentemente, desconforto ou medo para maioria. Somando o score das respostas dos futuros, podemos afirmar que 9 (nove) pessoas fizeram 3 (três) pontos; 7 (sete) marcaram 2 (dois); 6 (seis) 4 (quatro) pontos e 1(uma) pessoa contabilizou 1(um) ponto. Frente aos dados, podemos inferir que somando as marcações "discordo totalmente" e "discordo" totalizam 15 (quinze) estudantes [69,5\%] demonstrando não ter sentimentos negativos e 8 (oito) [30,5\%] responderam "concordo" e "concordo totalmente" afirmando o medo que sentem, ou seja, marcaram uma pontuação que revelou sentimentos negativos. Ao associar esta afirmação com a questão anterior (a do questionário), em que os futuros professores puderam com apenas uma palavra declarar qual sentimento definem ao pensar que terão que ensinar Matemática, é possível perceber que para eles passar pelo processo de aprendizagem no curso de Pedagogia não lhes causam sentimentos negativos, contudo, essa realidade modifica-se quando são convidados a reflexão sobre a futura atuação profissional.

O gráfico 3, presente na figura abaixo, apresenta uma afirmação positiva demonstrando qual a atitude predominou na turma investigada: 

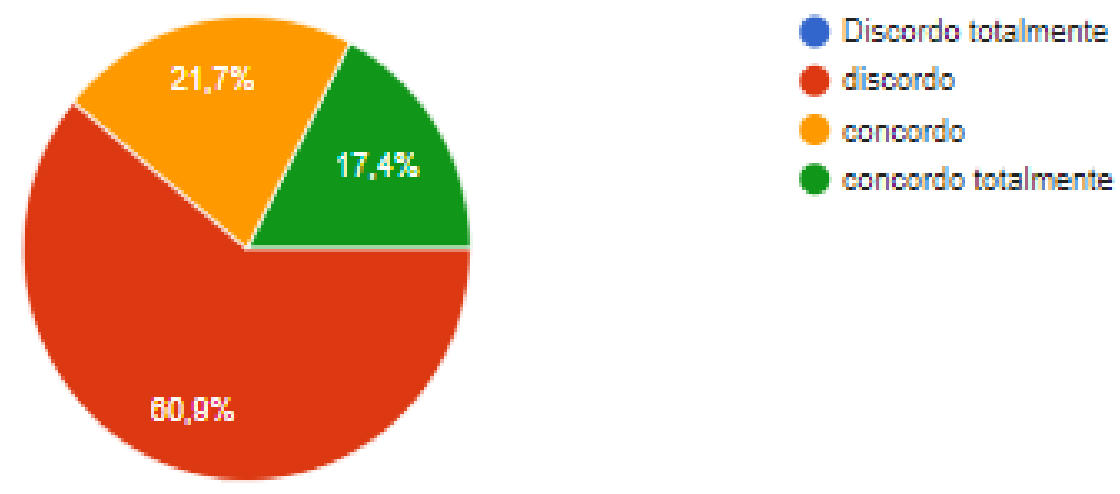

Figura 6 - Questão N. 9: "O sentimento que tenho com relação à Matemática é bom".

Diante da afirmação positiva, de acordo com catalogação das respostas, predominou "discordo" com 60,9\% representando 14 estudantes; seguido de "concordo" perfazendo $21,7 \%$ com 5 respostas e 17,4\% "concordo totalmente" sendo a afirmativa de 4 pessoas. Assim, temos na leitura interpretativa do score da "Escala de Atitudes", 14 (quatorze) pessoas com 2 (dois) pontos ao discordar; 5 (cinco) com 3 (três) concordando e 4 (quatro) marcam 4 (quatro) pontos. Logo, temos um número significativo de respostas das questões elegidas para apreciação, que sinalizam para atitudes negativas em relação à Matemática quando comparadas com as positivas, como vimos.

$\mathrm{Na}$ análise desta pergunta, é possível constatar que embora na afirmação anterior (respostas do gráfico 2 da figura 5), na qual grande parte afirma não temer cursar a matéria, o sentimento predominante ainda é o negativo. Tentar entender o porquê desse sentimento faz pensar fatores decorrentes de suas experiências e a relação que tiveram com a Matemática ao longo da Educação Básica. Numa perspectiva semelhante, Faria, Moro e Brito (2008, p. 258-259) apontam que:

[...] as pesquisas que tem buscado compreender a influência do professor na geração de atitude negativa (acerca da matemática), se enquadra dentro de um conjunto de estudos que se referem às suas crenças, atitudes, valores, concepções, ansiedade, percepções, expectativas e tipo de relação que este mantém com o aluno, seja diretamente, ou por meio da metodologia de ensino adotada [...]. Os resultados dessas pesquisas destacam também que a atitude negativa em relação à matemática (presente na atividade docente) contribui negativamente para o processo de aprendizagem dos alunos.

Recebido em: $30 / 03 / 2020$

Aceito em: 18/09/2020 
Essa questão vem ao encontro com o que o grupo pesquisado em nosso trabalho respondeu no questionário, onde indagou-se acerca das experiências anteriores com a disciplina, se consideravam que gostavam de Matemática e qual a justificativa para tal resposta. A resposta da maioria fez referência às influências de professores da Educação Básica para a formação de atitudes negativas, principalmente, ao relacionar as metodologias de ensino adotadas, afirmando que o professor tem peso significativo na forma como seus alunos se relacionam com a Matemática.

O gráfico 4 da figura 7, reúne as respostas de uma afirmativa negativa da escala:
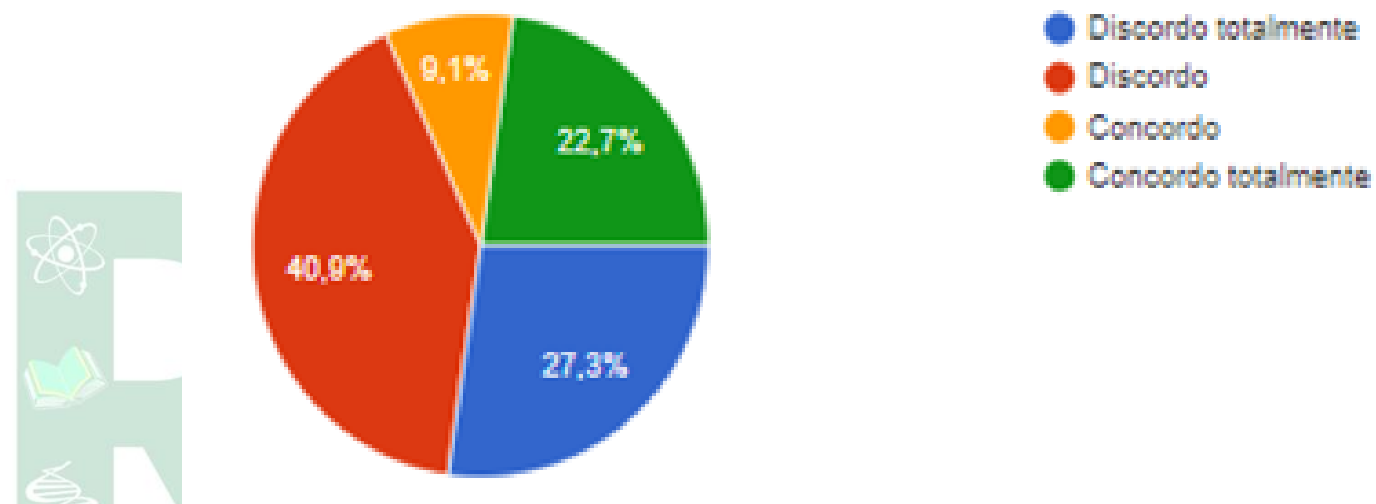

Figura 7 - Questão № 17: "Eu nunca gostei de Matemática e é a matéria que me dá mais medo".

Como podemos verificar, nesta afirmação 9 (nove) respostas $(40,9 \%$ ) referenciam "discordo"; 7 (sete) que representam 27,3\% para "discordo totalmente"; 5 (cinco), 22,7\%, em "concordo" e 9,1\% que são 2 (duas) pessoas afirmaram "concordo totalmente". Somando o score dos participantes, 9 (nove) marcaram 3 (três) pontos; 7 (sete) fizeram 4 (quatro); 5 (cinco) 2 (dois) pontos e, finalizando, 2 (duas) respostas pontuaram 1 (um), ou seja, do quantitativo geral 68\% (16) futuros professores parecem, ao que os dados indicam, terem atitudes positivas, pois discordam da afirmação negativa, o que sinaliza para um sentimento positivo da maioria nesta questão, quando se compara os $31,8 \%$ (7) que reforçam atitudes negativas.

Embora na questão anterior, a de N. 9 apresentada no gráfico 3 (figura 6), ter predominado sentimento negativo, ao observarmos as respostas da afirmativa do gráfico 4 (figura 7), que ao discordar, declaram que em algum momento gostaram da disciplina e que a Matemática não é a matéria que mais lhes causam medo. Podemos inferir que há um sentimento positivo, o que reforça a tese de que a formação inicial poderia ser o 
espaço facilitador para mudança de atitudes, principalmente, desses 31,8\% que chegam à graduação com sentimentos negativos. Esse dado, também contribui com a afirmação de Faria (1996, p. 12) quando compreende ser a formação inicial de professores, "[...] um campo fértil para o desenvolvimento de atitudes positivas em relação à Matemática [...]", é, neste momento, que os acadêmicos têm experiências que lhes possibilitam construir compreensões sobre o ensino e a aprendizagem de conceitos, encontram oportunidade de ampliação do repertório didático-pedagógico e ainda chegam a ressignificação dos saberes e conhecimentos decorrentes de experiências ao longo do processo de escolarização. Por essa razão, julgamos pertinente o papel que a licenciatura em Pedagogia pode representar aos futuros pedagogos, isso coloca em xeque a problematização do perfil do formador de professores, muito embora não seja esse o foco da discussão aqui exposta, mas, afirmamos ser necessário explicitar tal constatação.

A última das questões em análise fora a em destaque no gráfico 5 ilustrado na figura 8:

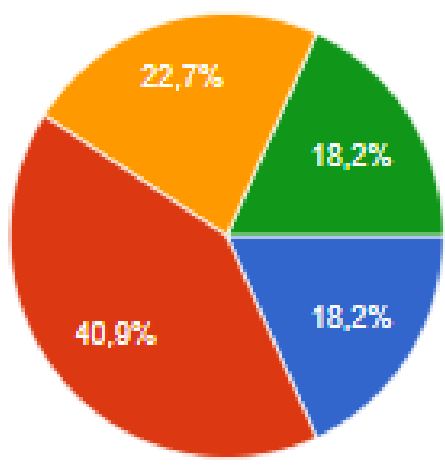

Discordo totalmente

Discordo

Concordo

Concordo totalmente

Figura 8 - Questão N. ${ }^{\circ}$ 20: "Eu tenho uma reação definitivamente positiva com relação à Matemática: Eu gosto e aprecio essa matéria".

A afirmação posta acima faz menção à atitude positiva, os dados desta sinalizam que 40,9\% (9) discordam; 22,7\% (6) afirmam "concordo"; 18,2\% (4) responderam "discordo totalmente" e 18,2\% (4) "concordo totalmente". Somando o score, a pontuação é de 2 (dois) para 9 (nove) futuros professores discordaram; 3 (três) para 6 (seis) que concordaram; 4 (quatro) pontos para 4 (quatro) que concordaram totalmente e 1 (um) para 4 (quatro) que discordaram totalmente, tendo um percentual de 59,1\% (13) 
delineando um sentimento negativo e 40,9\% (10) que juntos demarcam sentimento positivo.

De acordo com as informações coligidas com base nas respostas das afirmações destacadas na "Escala de Atitudes" objeto de análise até aqui referenciadas, podemos inferir que existe a presença de um desconforto ao afirmar que a relação com a Matemática é positiva. Fica evidente que os sentimentos se alternam e oscilam ora para atitudes positivas, ora para atitudes negativas. Ainda que a relação com a Matemática não seja algo considerado bom, a posição ocupada como estudantes os deixam confortáveis/seguros para aprender e ressignificar seus sentimentos e atitudes, a insegurança, medo e sentimentos negativos ficam evidentes quando eles se colocam na posição de futuros professores, voltando na fala inicial dos estudantes em "temer" ao pensar em ensinar o que não "dominam" do ponto de vista conceitual, daí a importância da discussão em torno dessa temática na formação inicial, pois durante a trajetória acadêmica pode haver modificação das atitudes influenciando em sua futura atividade profissional, haja vista que as atitudes não são inatas. O estudo de Faria (2006) permitiu ponderar o processo reverso em que os acadêmicos, ao ingressarem no curso de licenciatura, mudaram de atitude em relação à Matemática de positiva para negativa. É possível que uma atitude positiva tenha contribuído para a escolha da licenciatura, mas as experiências vivenciadas logo no início do curso alteraram essa atitude, ou seja, mudam o percurso de como o sujeito (futuro docente) se enxerga em determinado campo de conhecimento.

Face ao trabalho que temos realizado, com a investigação de mestrado em Educação Matemática em desenvolvimento, concordamos com a explicação de Brito (1996) que as mudanças no curso de Pedagogia vão além de aumentar ou diminuir carga horária de disciplinas ou até mesmo incluir ou excluir disciplinas. De acordo com a autora, repensar a formação de professores que ensinam Matemática "[...] envolve uma mudança de atitudes dos indivíduos com relação ao ensino e à formação de professores (sua relevância e importância) e elas não ocorrem a curto prazo" (BRITO, 1996, p. 15).

\section{CONCLUSÕES}

Com base nos dados produzidos e aqui explorados inicialmente, ainda que de forma embrionária, é possível perceber a insegurança, medos e dúvidas relacionados com os sentimentos que a maior parte dos futuros professores chegam no Ensino 
Superior. Desse modo, podemos inferir que, ao que tudo indica, parecem existir elementos que sinalizam para a relevância da formação inicial para o desenvolvimento de atitudes. Para nós, as ações que licenciatura poderiam contribuir evolvem em tentar "quebrar" certas barreiras acerca do processo de ensino e aprendizagem matemática ao se apresentar tendências em Educação Matemática que possibilitem, aos estudantes, compreender o fazer matemático na sala de aula dos anos inicias como, por exemplo, a abordagem conceitual dos conteúdos a partir de situações-problemas reais que visem incorporar modelagem matemática, resolução de problemas, tecnologia, história da Matemática, jogos, materiais manipuláveis, entre outros.

Tudo isso, somado às práticas que permitem aumentar a crença de que são capazes de ensinar poderá contribuir, de forma significativa, para atitudes mais positivas, ainda que não se resolva todos os déficits decorrentes da falta de especificidades da presença da Matemática em cursos de Pedagogia, esta pode ser uma das alternativas de se minimizar os problemas.

Em síntese, podemos concluir, para o momento, que estudar a formação de atitudes implica reconhecer que a análise dos problemas que atingem diretamente a forma como vemos um determinado objeto como, por exemplo, a Matemática, não se dá/ocorre separadamente da relação pessoal que criamos ao longo do ciclo de vida pessoal com esta. Isso, sem dúvida, nos leva a reconhecer a importância de se investigar a temática em movimentos contínuos que se dão da formação inicial ao desenvolvimento profissional, em ações de formação após a indução na docência.

\section{REFERÊNCIAS}

BRITO, Márcia Regina Ferreira de. Um estudo sobre as atitudes em relação à Matemática em estudantes de 1 e 2 graus. Campinas, SP. 398f. Tese (Livre Docência) na área de Aprendizagem do Departamento de Psicologia Educacional da Faculdade de Educação UNICAMP, 1996. Disponível em: http://repositorio.unicamp.br/jspui/handle/REPOSIP/251566. Acesso em: 8, fev. 2019.

Adaptação e validação de uma escala de atitudes em relação à matemática. Zetetiké, Campinas, v. 6, n. 9, p. 109-162, 1998. Disponível em: https://periodicos.sbu.unicamp.br/ojs/index.php/zetetike/article/view/8646811/13713. Acesso em: 17, mar. 2020.

CIRÍACO, Klinger Teodoro; TEIXEIRA, Leny Rodrigues Martins. Elementos constitutivos da prática pedagógica nas aulas de matemática: os saberes adquiridos nos cursos de formação inicial em pedagogial. Revista Paranaense de Educação 
Matemática, $\quad$ v. $3, \quad$ n. $\quad 5, \quad 2015 . \quad$ Disponível em: http://rpem.unespar.edu.br/index.php/rpem/article/viewFile/922/pdf_101. Acesso em: 12, fev. 2020.

CURI, Edda. Formação de professores polivalentes: uma análise de conhecimentos para ensinar Matemática e de crenças e atitudes que interferem na constituição desses conhecimentos. São Paulo, SP. 278f. Tese (Doutorado em Educação Matemática). Pontifícia Universidade Católica de São Paulo, PUC-SP, 2004.

FARIA, Paulo Cézar de. A formação do professor de matemática: problemas e perspectivas. 1996, 138f. Dissertação (Mestrado em Educação). Universidade Federal do Paraná, UFPR, Curitiba-PR. 1996.

FARIA, Paulo Cézar; MORO, Maria Lucia Faria; BRITO, Márcia Regina Ferreira de. Atitudes de professores e futuros professores em relação à Matemática. Estudos de Psicologia (Natal), v. 13, n. 3, p. 257-265, 2008. Disponível em: http://www.scielo.br/scielo.php?pid=S1413-294X2008000300008\&script=sci_arttext.

Acesso em: 23, mar. 2020.

FARIA, Paulo Cézar de; CAMARGO, Brigido Vizeu; MORO, Maria Lucia Faria. Indicadores de atitude de estudantes e professores com relação à Matemática. Paidéia (Ribeirão Preto), v. 19, n. 42, p. 27-37, 2009. Disponível em: http://www.scielo.br/pdf/paideia/v19n42/05.pdf. Acesso em: 13, mar. 2020.

FIORENTINI, Dario. A pesquisa e as práticas de formação de professores de matemática em face das políticas públicas no Brasil. Boletim de Educação Matemática, v. 21, n. 29, p. 43-70, 2008. Disponível em: http://www.periodicos.rc.biblioteca.unesp.br/index.php/bolema/article/view/1718/.

Acesso em: 15, fev. 2020

GOMES, Maristela Gonçalves. Obstáculos na aprendizagem matemática: identificação e busca de superação nos cursos de formação de professores das séries iniciais. 2006. 161f. Tese (Doutorado em Educação Científica e Tecnológica) Universidade Federal de Santa Catarina - UFSC, Florianópolis-SC. 2006. Disponível em:

https://repositorio.ufsc.br/bitstream/handle/123456789/89346/231630.pdf?sequence=1\& isAllowed=y. Acesso em: 12, fev. 2020.

GONÇALEZ, Maria Helena Carvalho de Castro. Atitudes (des) favoráveis com relação à Matemática. Campinas, SP. 1995. 147f. Dissertação (Mestrado em Educação). Universidade Estadual de Campinas - UNICAMP, Campinas-SP. 1995. Disponível em: http://repositorio.unicamp.br/jspui/handle/REPOSIP/251628. Acesso em: 10, mar. 2019.

MINAYO, Maria Cecília Souza. (org). Pesquisa social: teoria, método e criatividade. 33a . ed. Petrópolis, RJ: Vozes, 2013.

MORAES, Mara Sueli Simão; PIROLA, Nelson Antonio. Atitudes positivas em relação à Matemática. In: BRASIL, Ministério da Educação. Secretaria de Educação Básica. 
Diretoria de Apoio à Gestão Educacional. Pacto Nacional pela Alfabetização na Idade Certa. Alfabetização matemática na perspectiva do letramento. Brasília, DF: MEC;
SEB,
2015.
(Caderno,
7). p.62-72.
Disponível
em:

http://www.serdigital.com.br/gerenciador/clientes/ceel/material/148.pdf. Acesso em: 13, out. 2019.

NACARATO, Adair Mendes; MENGALI, Brenda Leme da Silva; PASSOS, Cármen Lúcia Brancaglion. A Matemática nos anos iniciais do Ensino Fundamental: tecendo fios do ensinar e do aprender. Autêntica Editora, 2019.

PONTE, João Pedro. Saberes profissionais, renovação curricular e prática letiva. In: BLANCO NIETO, Lorenzo; JIMÉNEZ, Vicente Mellado. (coords.) La formación del professorado de Ciencias y Matemáticas en España y Portugal. Imprenta de la Excma. Diputación Provincial de Badajoz. p.187-201, 1995. Disponível em: https://www.eweb.unex.es/eweb/dcem/L95FormProfEspyPort.pdf. Acesso em: 12, out. 2019.

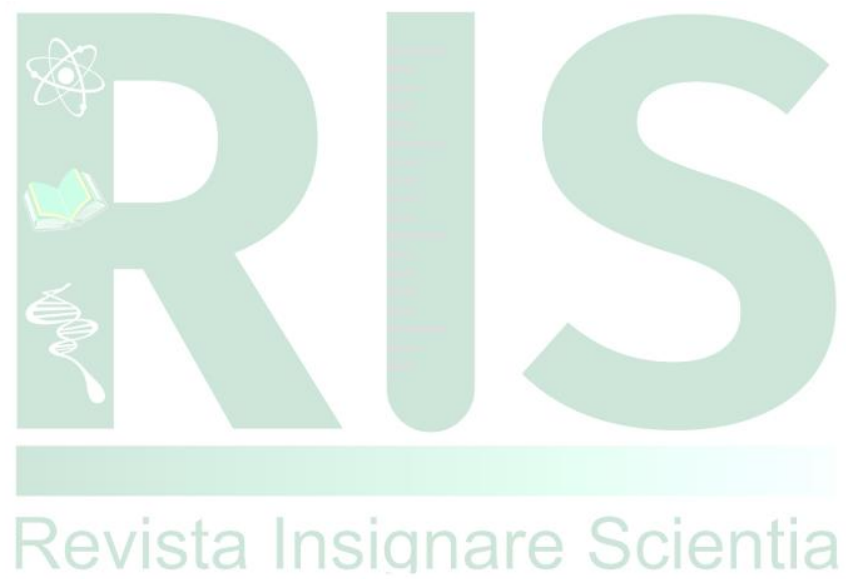

